\title{
Numerical Test Research on Loading Rate Effect of Rock Mass with Transfixion Sawtooth Structural Plane
}

\author{
Dongsong Li $\mathbb{D},{ }^{1}$ Yanhong Du $\mathbb{D},{ }^{2}$ Feng Chen $\mathbb{D}^{2},{ }^{2}$ and Tianhui Ma $\mathbb{D}^{3}$ \\ ${ }^{1}$ Department of Road and Bridge Engineering, Liaoning Provincial College of Communications, Shenyang, China \\ ${ }^{2}$ School of Mechanics and Engineering, Liaoning Technical University, Fuxin 123000, China \\ ${ }^{3}$ School of Civil Engineering, Dalian University of Technology, Dalian 116024, China \\ Correspondence should be addressed to Tianhui Ma; tianhuima@dlut.edu.cn
}

Received 20 July 2020; Revised 16 October 2020; Accepted 21 October 2020; Published 6 November 2020

Academic Editor: Fengqiang Gong

Copyright ( $\odot 2020$ Dongsong Li et al. This is an open access article distributed under the Creative Commons Attribution License, which permits unrestricted use, distribution, and reproduction in any medium, provided the original work is properly cited.

In this paper, numerical test research is carried out on the loading rate effect of a numerical specimen (sample C) with a transfixion sawtooth structural plane by using the rock failure process analysis (RFPA) 2D software. In order to study the mechanical characteristics difference between the rock mass with this kind of structural plane and other rock masses, the intact numerical specimen (sample A) of no structural plane and the numerical specimen (sample B) with smooth structural plane are also simulated. The uniaxial compression tests were carried out for each specimen under five loading rates of $0.002,0.005,0.008,0.02$, and $0.05 \mathrm{~mm} / \mathrm{s}$. The following several conclusions are obtained by the numerical test. When the loading rate is $0.002 \mathrm{or} 0.005 \mathrm{~mm} /$ $\mathrm{s}$, the failure mode of the numerical specimen $\mathrm{C}$ is an inclined linear fracture zone located in the middle and lower part of the rock mass; however, when the loading rate rises to $0.008,0.02$, and $0.05 \mathrm{~mm} / \mathrm{s}$, the fracture zone of the numerical specimen $\mathrm{C}$ is located in the middle and upper part of the rock mass, and its inclination angle is about 60 degrees. The peak strength, residual strength, and stress drop of the specimens $\mathrm{A}, \mathrm{B}$, and $\mathrm{C}$ increase with the addition of loading rate; the peak strength and stress drop of the sample $\mathrm{C}$ are higher than those of the other two samples. When the loading rate is $0.002 \mathrm{~mm} / \mathrm{s}$, the residual strength of sample $\mathrm{C}$ is lower than that of samples A and B, and the other four kinds of loading conditions are higher than those of specimens $\mathrm{A}$ and $B$. Based on the acoustic emission (AE) information, it can be seen that the failure modes of the numerical specimen $\mathrm{C}$ under five loading conditions are tensile failure. The AE accumulated energy decreases with the increase of loading rate, but the change law of AE accumulated number is opposite.

\section{Introduction}

Rock is subjected to various tectonic actions in complex geological environment, resulting in the structural planes with different shapes and various scales $[1,2]$. The sawtooth structural plane is widely distributed in natural slope and excavating engineering slope of rock mass [3]. As shown in Figure 1, there is an undulate surface at the Aishihik River Landslide in Canada, and Figure 2 shows the sawtooth structural plane in a pit created by rockburst damage [4]. It is well known that so many calamities occur frequently on the structural surface in a variety of rocks' engineering $[5,6]$. Therefore, it is a very important reference value to study the failure process of rock masses with various shapes and structures for further understanding the occurrence of rock mass engineering disaster.

For more than 100 years, scholars from all over the world have done specialized research on the deformed failure process and strength characteristics of rock mass with structural planes, and many achievements have been obtained. Blanton [7] suggested that the energy necessary to fragment the unconfined rocks is lower at higher strain rates. Martin [8] investigated the uniaxial compressive strength of rock increases in the wake of the increase of loading rate by means of experimental results. Li [9] carried out uniaxial compression experiments on red sandstone under diverse loading rates and analyzed the influence of strain rate on fracture forms. Backers et al. [10] found that the fracture 


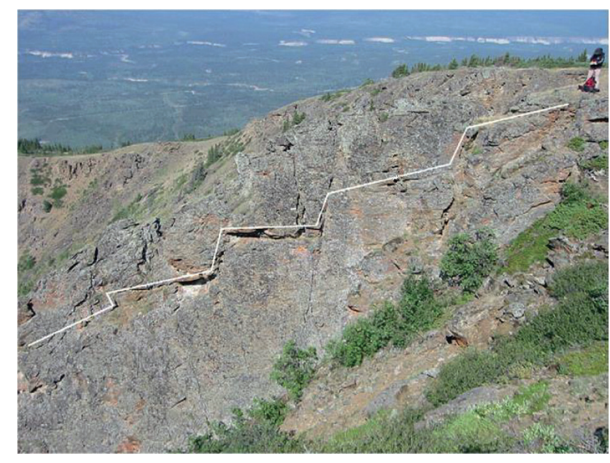

Figure 1: An undulate surface at the Aishihik River Landslide in Canada [3].

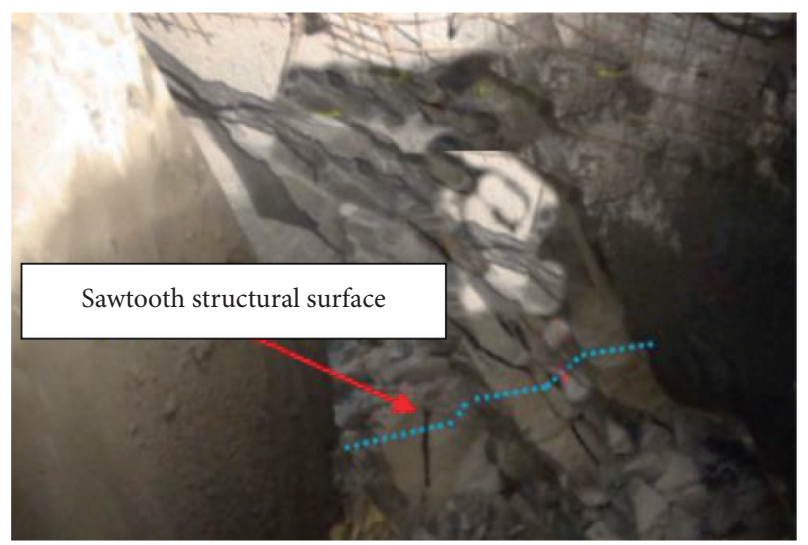

FIGURE 2: Sawtooth structural plane in a pit created by rockburst damage [4].

toughness of rock and the roughness of rock fracture surface also have loading speed influence. Yang et al. [11] pointed out that in the indoor test of uniaxial compression with different loading rates for the limestone, the peak strength of limestone is enhanced with the increase of loading rate, and in a certain range, faster loading rate makes the specimen's falling curve that from the peak strength to the residual strength more steeply. Fuenkajorn and Kenkhunthod [12] studied the loading rate formulation of deformability and shear strength for the elastic and isotropic rocks. Gong et al. [13] analyzed the correlation between the failure modes of sandstone specimens and the characteristics of stress-strain curves under different strain rates.

Both the physical and numerical tests on the mechanical characteristics of rock masses with different loading rates consider that the structural surface is smooth, and the undulating pattern of the structural surface is not considered till now [14-16]. The discontinuities of rock medium can be caused by the existence of structural planes and the fluctuation of structural planes, while the RFPA software takes into account the discontinuity of the material properties, the heterogeneity, and the randomness of the defect distribution. Based on these characteristics of RFPA software, this paper uses RFPA to simulate the failure characteristics of transfixion-type regular sawtooth structural surface rock under different loading rates. The variation characteristics of peak strength, residual strength, and acoustic emission quantity in three kinds of numerical tests have been discussed. The influence of loading rate on failure mode of rock mass has been analyzed by using $\mathrm{AE}$ diagram.

\section{A Brief Introduction to the Principles of RFPA Calculation}

RFPA is a numerical test tool that simulates the whole process of progressive rupture of materials until they are instability. An important feature of the method is considering the inhomogeneity of the material properties. By considering heterogeneity, RFPA can simulate nonlinear behavior of rock in macroscale with linear method in mesoscale [17-19]. By introducing the concept of mathematical continuity and physical discontinuity, RFPA can simulate rock failure in terms of material property degradation. RFPA computing process is mainly completed by the following three parts:

(1) Solid modeling and mesh dividing: the user selects element types (entities, supports, or cavities), defines the mechanical properties of the medium, and performs entity modeling and mesh generation.

(2) Stress calculation: stress and strain analysis, the stiffness matrix is formed according to the boundary conditions and loading control parameters input by the user and input primitive property data. The finite element calculation result (stress, node displacement) is solved and output.

(3) Elementary phase transition analysis: according to the phase change criterion, the phase transformation is judged by the results of the stress solver, then the phase change elements are weakened or reconstructed, and finally the data files that needed iteratively calculating the stiffness matrix are formed.

\section{Numerical Test Design}

3.1. Numerical Specimens Design. The influence of the regular sawtooth structure on the mechanical properties of rock mass is studied in this paper. The failure feature's similarities and differences between rock mass with transfixion regular sawtooth structure and intact rock mass, rock mass including a smooth transfixion structural plane are analyzed by means of comparison method. On the basis of the relevant regulations of rock mechanics interior laboratory, three kinds of two-dimensional numerical specimens are established by RFPA software, which are marked as A (numerical specimens of intact rock mass without structural plane), B (numerical specimens of rock mass with a smooth transfixion structural plane), and C (numerical specimens of rock mass with transfixion regular sawtooth structure), respectively, as shown in Figure 3. All of the sizes of A, B, and $\mathrm{C}$ are $50 \mathrm{~mm} \times 100 \mathrm{~mm}$ (width $\times$ height) and divided into 


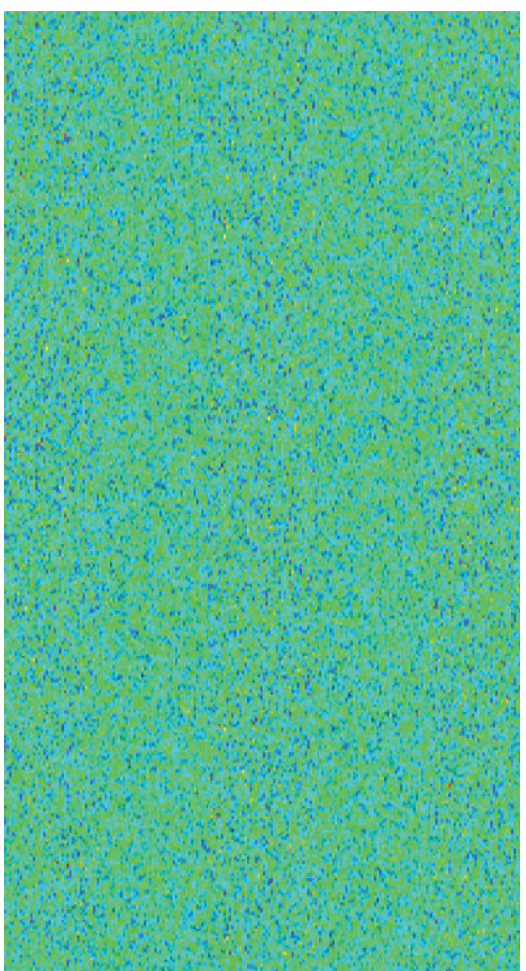

(a)

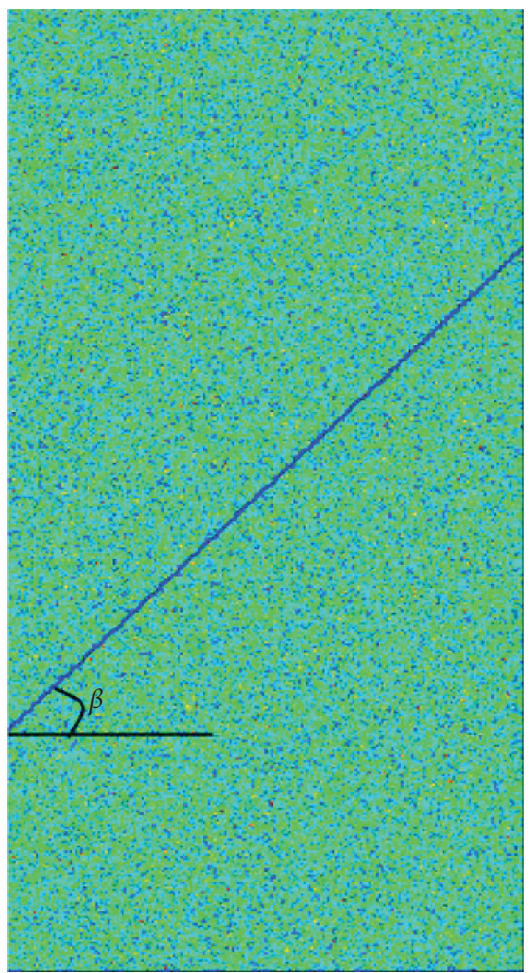

(b)

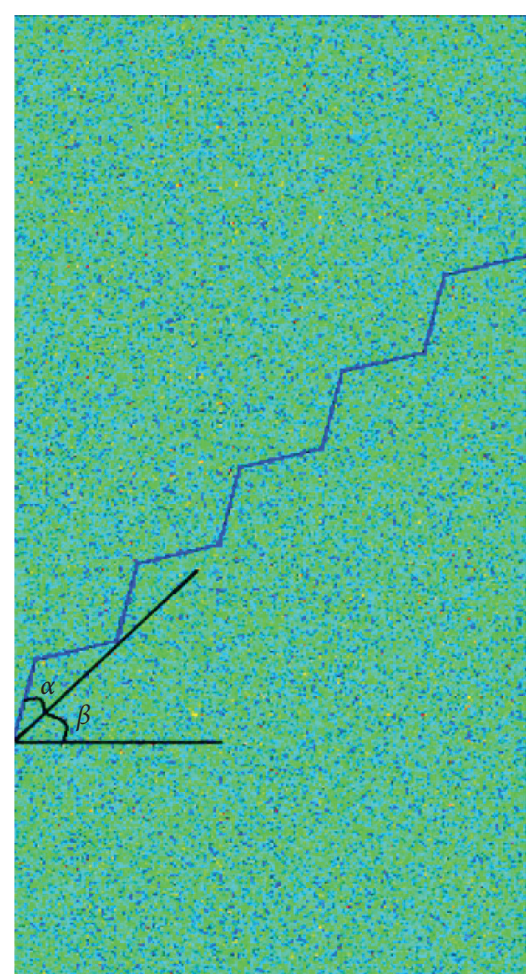

(c)

Figure 3: Three numerical specimens' models. (a) Numerical specimen A, (b) numerical specimen B, and (c) numerical specimen C.

$200 \times 400$ units; each cell's shape is square and the length of a side is $0.25 \mathrm{~mm}$. In the numerical specimen $B$, the inclination angle $(\beta)$ of the structural plane is designed to 45 degrees, so is sample $C$, and the undulate angle $(\alpha)$ of the structural surface is set to 30 degrees. The number of teeth of the regular sawtooth structural surface is 5 . The mechanical parameters adopted in the numerical specimens are shown in Table $1[20]$.

3.2. Loading Mode. The loading rate has an obvious influence on the mechanical properties of rock in uniaxial compression test [21-24]. Uniaxial compression test is carried out for three kinds of numerical specimens A, B, and C. They are, respectively, implemented at loading rates of $0.002,0.005,0.008,0.02$, and $0.05 \mathrm{~mm} / \mathrm{s}$, until the rock sample is broken and the loading is finished. This is equivalent to simulating the damage of rock mass at different loading rates under the action of geological tectonic or engineering loads [25].

\section{Numerical Simulation Results and Analysis}

The mechanical characteristics of rock mass with transfixion regular sawtooth structural surface under different loading rates are studied in this paper. At the same time, the distinctions in the mechanical properties of the numerical specimens $\mathrm{A}, \mathrm{B}$, and $\mathrm{C}$ are discussed by lateral contrast method and longitudinal contrast method. Among them, the lateral contrast refers to the comparison of the mechanical properties of the same type of specimens at different loading rates; longitudinal contrast refers to the comparison of the mechanical characteristics of distinguished types of specimens at the same loading speed.

4.1. Failure Feature Analysis. In order to exhibit vividly the shape of the main fracture zone in the failure of numerical specimens, the deformation amplification coefficient in RFPA is set to 20. Figure 4 shows the numerical test result of the specimen $\mathrm{C}$. In the $\mathrm{AE}$ picture, the size of the circle represents the size of the relative energy or magnitude, which is proportional to the intensity of the element. The white circle stands for shear failure, and the red circle stands for tension fracture. Using acoustic emission technique to study the occurrence and development of microcracks in rock under different loading rates is conducive to understand rock rupture process and deformation law comprehensively and truly [26, 27].

It can be found out from Figure 4 that when the loading rates are $0.002 \mathrm{~mm} / \mathrm{s}$ and $0.005 \mathrm{~mm} / \mathrm{s}$, the main zone of faulting is located in the lower part of the sample and is inclined; its breaking angle (the acute angle between the main fracture zone and the horizontal direction) is 
Table 1: Numerical specimen properties.

\begin{tabular}{lcccc}
\hline Parameter & Elastic modulus $(\mathrm{GPa})$ & Compressive strength $(\mathrm{MPa})$ & Homogeneity & Poisson's ratio \\
\hline Structural body & 30 & 100 & 2 & 0.26 \\
Structural plane & 3 & 10 & 1.5 & 0.26 \\
\hline
\end{tabular}
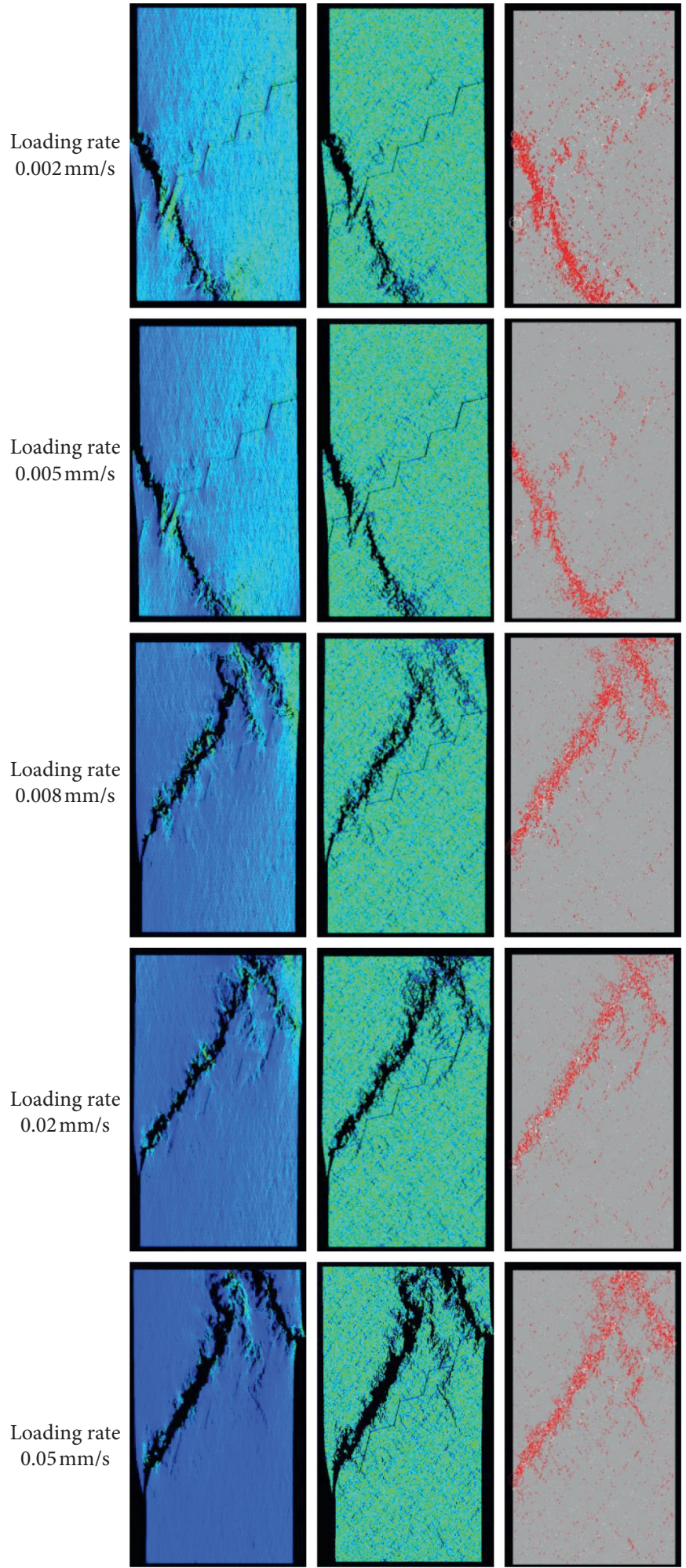

Maximum principal stress diagram

Elastic modulus diagram

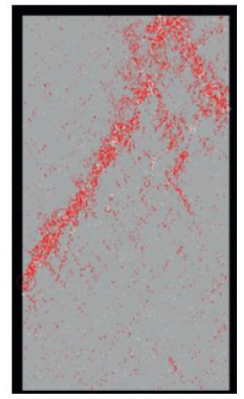

AE diagram

FIGURE 4: Failure mode of the numerical specimen $\mathrm{C}$ under different loading rates. 
approximately 65 degrees after the specimens are destroyed. From the corresponding AE diagram, it is found that the fracture zone is covered with red circle, which apparently indicates that the failure mode of the numerical specimen is tensile failure. When the loading rate ascends to $0.008,0.02$, and $0.05 \mathrm{~mm} / \mathrm{s}$, there is an inclined linear pattern of the main failure zone that locates the upper part of the sample after the specimens' wreck, and the fracture angle is almost 60 degrees. At the same time, the relevant AE diagram shows that the AE type is tensile when the sample breaks; it indicates that tensile failure occurs under the action of external force.

4.2. Strength Characteristics. Peak strength is the maximum axial compressive stress when the rock failure occurs. The rock specimen still has a certain carrying capacity after rupture, but only a small stress value is maintained, which calls residual strength. Stress drop refers to the difference between peak strength and residual strength.

Figure 5 shows the relationship between peak strength and loading rate, Figure 6 shows the relationship between residual strength and loading rate, and Figure 7 shows the relationship between stress drop and loading rate. As can be seen from Figures 5 and 6 , the peak strength of the numerical specimens $\mathrm{A}, \mathrm{B}$, and $\mathrm{C}$ rises with the increasing loading rate. The residual strength of the numerical specimens $\mathrm{A}$ and $\mathrm{C}$ grows as the loading rate increases; however, the residual strength of sample B appeared to decrease first and then increase, and the lowest point appeared at the loading rate of $0.008 \mathrm{~mm} / \mathrm{s}$. The stress drops of the numerical specimens A, $\mathrm{B}$, and $\mathrm{C}$ increase with the increase of loading rate, as shown in Figure 7.

In these five kinds of loading rate, the maximum value of peak strength of numerical specimens $\mathrm{A}, \mathrm{B}$, and $\mathrm{C}$ is 1.46 times, 1.96 times, and 1.53 times their minimum value, respectively. The peak strength $(\beta)$ is approximately linear with the loading rate $(v)$. The fitting results are as follows by the formula $\alpha=M v+N$ ( $M$ and $N$ are both fitting coefficients):

$$
\begin{aligned}
\beta & =951464 v+95.662\left(\text { numerical specimens } C, R^{2}=0.9536\right), \\
\sigma_{f} & =999501 v+53.023\left(\text { numerical specimens } B, R^{2}=0.9835\right), \\
\sigma_{f} & =798879 v+87.969\left(\text { numerical specimens } A, R^{2}=0.97\right) .
\end{aligned}
$$

Figures 8-10 are the contrast diagrams of peak strength, residual strength, and stress drop for different types of numerical specimens at the same loading rate. As can be seen from Figure 8, at the same loading rate, the peak strength of numerical specimen $\mathrm{C}$ is the highest, the peak strength of sample A is the second, and the peak strength of sample B is the lowest. As shown in Figure 9, it is found that the residual strength does not appear to be the identical law as the peak strength at the same loading rate. When the loading rate is $0.005,0.008,0.02$, and $0.05 \mathrm{~mm} / \mathrm{s}$, the residual strength of the numerical specimen $\mathrm{C}$ is the highest. At the loading rate of $0.002 \mathrm{~mm} / \mathrm{s}$, the residual strength of the numerical specimens $C$ is minimum. As can be seen from Figure 10, with the same loading rate, the stress drop from high to low is the numerical sample $\mathrm{C}$, the numerical sample $\mathrm{A}$, and the numerical sample $B$.

\subsection{AE Accumulated Energy and AE Accumulated Counts} Characteristics. When a rock produces microrupture under an external force, a portion of the strain energy is released in the form of an elastic wave, which is called the acoustic emission (AE) of rock. The observation and analysis of this elastic wave is the AE technique of rock. Each AE signal contains information that reflects the internal defects in the rock [28]. After the specimen is destroyed, the AE accumulated energy and the $\mathrm{AE}$ accumulated counts are the characteristic parameters of rock failure. The test results are shown in Figure 11.

From the transverse comparison, it can be seen that $\mathrm{AE}$ accumulated counts of the numerical specimens A, B, and C grow with the loading rate increasing; however, the $\mathrm{AE}$ accumulated energy of numerical specimen A shows the opposite law, which decreases with the increase of loading rate, as shown in Figure 11(a). The AE accumulated energy of numerical specimens B increases first and then decreases; when the loading rate is $0.005 \mathrm{~mm} / \mathrm{s}$, the $\mathrm{AE}$ accumulated energy appears maximum, as shown in Figure 11(b). The AE accumulated energy of numerical specimen $\mathrm{C}$ shows a general decreasing trend; the $\mathrm{AE}$ accumulated energy rises slightly while the loading rate is $0.02 \mathrm{~mm} / \mathrm{s}$, as shown in Figure 11(c).

From Figures 12 and 13, it can be seen that when the loading rate is $0.002,0.005$, and $0.008 \mathrm{~mm} / \mathrm{s}$, under the premise of complete failure of the specimen, the $\mathrm{AE}$ accumulated energy from high to low is the numerical specimens $\mathrm{B}, \mathrm{C}$, and $\mathrm{A}$; the $\mathrm{AE}$ accumulated counts from high to low is the numerical samples $\mathrm{C}, \mathrm{A}$, and $\mathrm{B}$. When the loading rate is increased by an order of magnitude, namely, the loading rate is 0.02 and $0.05 \mathrm{~mm} / \mathrm{s}$; when the sample is completely destroyed, the $\mathrm{AE}$ accumulated energy from high to low is the numerical samples $\mathrm{C}, \mathrm{A}$, and $\mathrm{B}$; the $\mathrm{AE}$ accumulated counts from high to low is the numerical samples $\mathrm{A}, \mathrm{C}$, and B. 


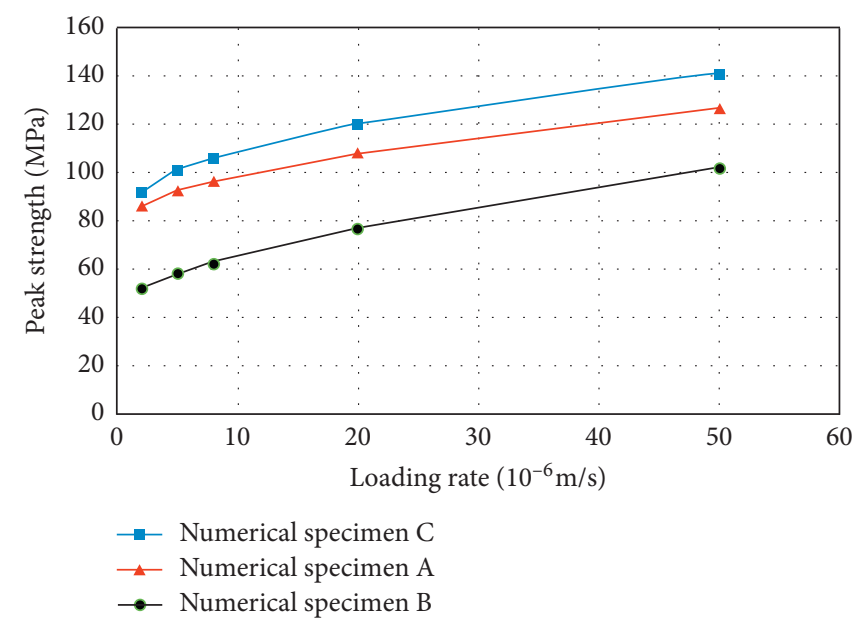

Figure 5: Relationship curve between peak strength and loading rate.

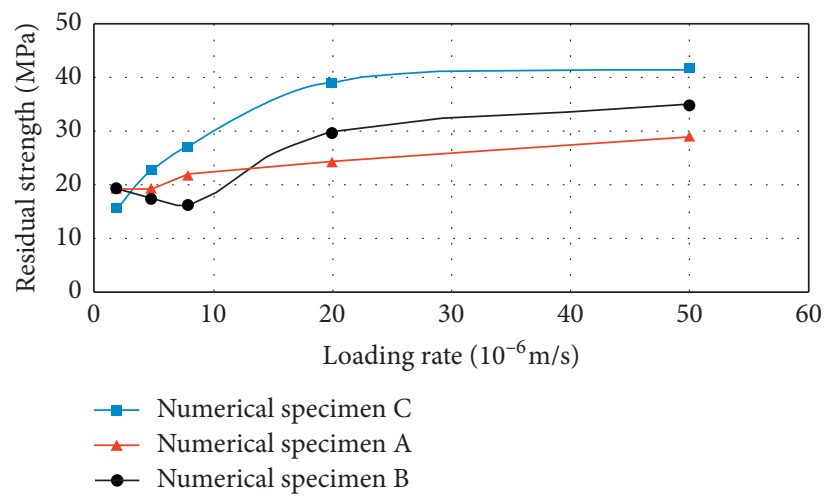

FIGURE 6: Relationship curve between residual strength and loading rate.

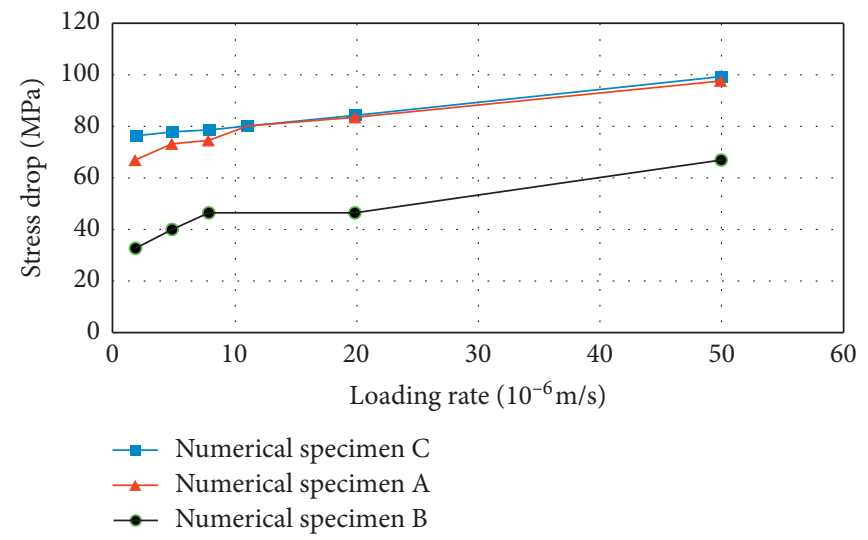

Figure 7: Relationship curve between stress drop and loading rate. 


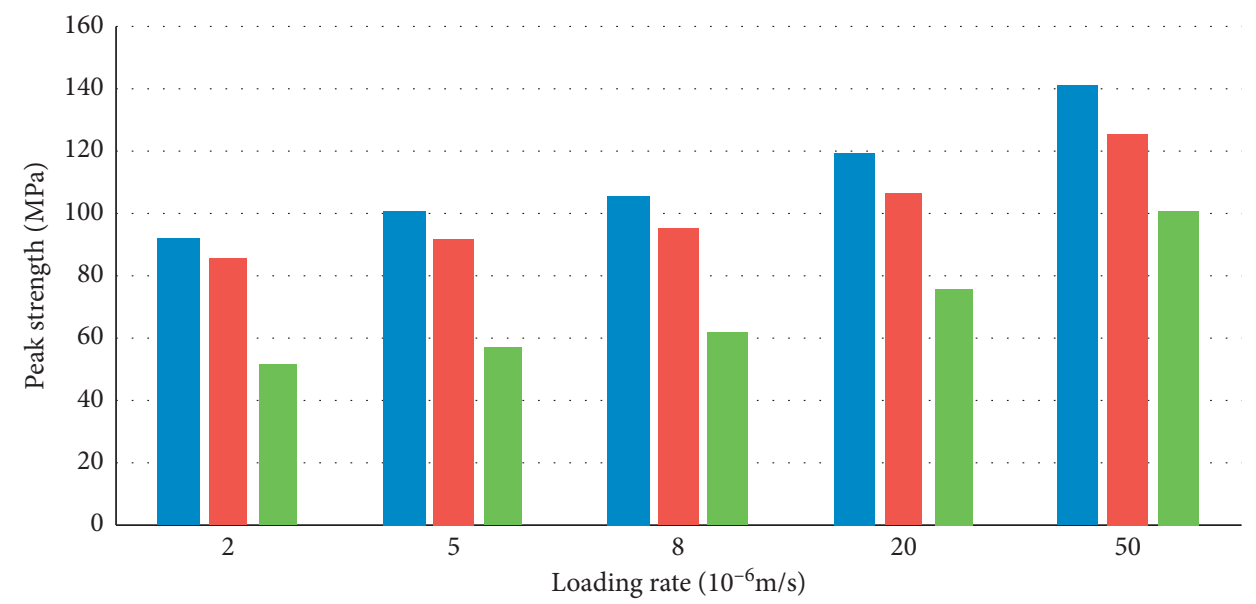

- Numerical specimen C

- Numerical specimen A

- Numerical specimen B

FIGURE 8: Longitudinal contrast of peak strength of three kinds of numerical specimens.

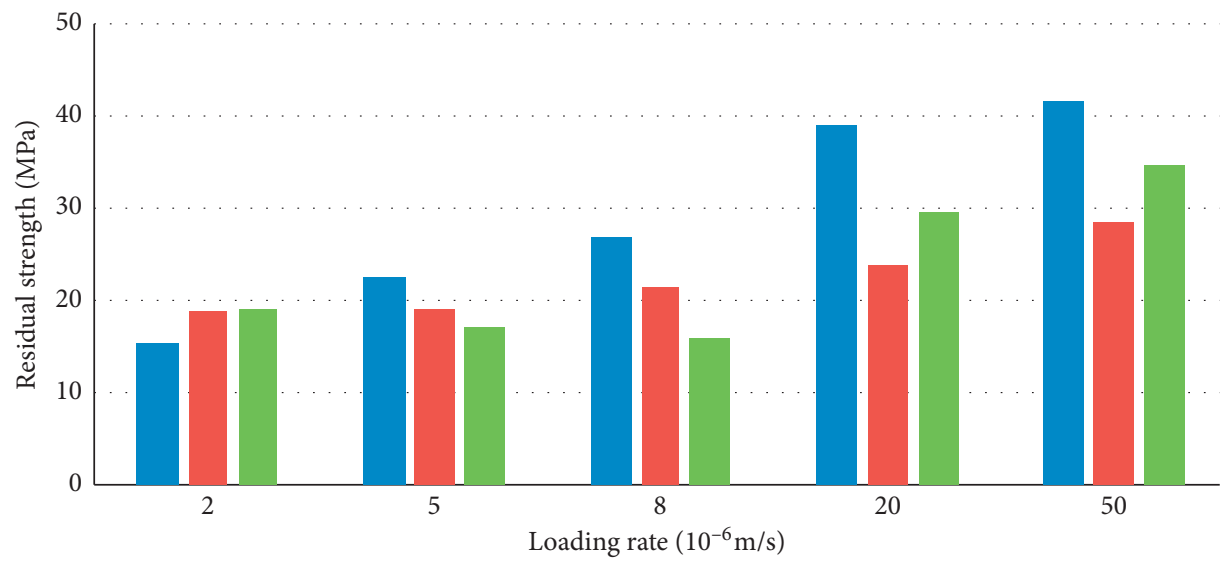

- Numerical specimen C

- Numerical specimen A

- Numerical specimen B

FigURE 9: Longitudinal contrast of residual strength of three kinds of numerical specimens.

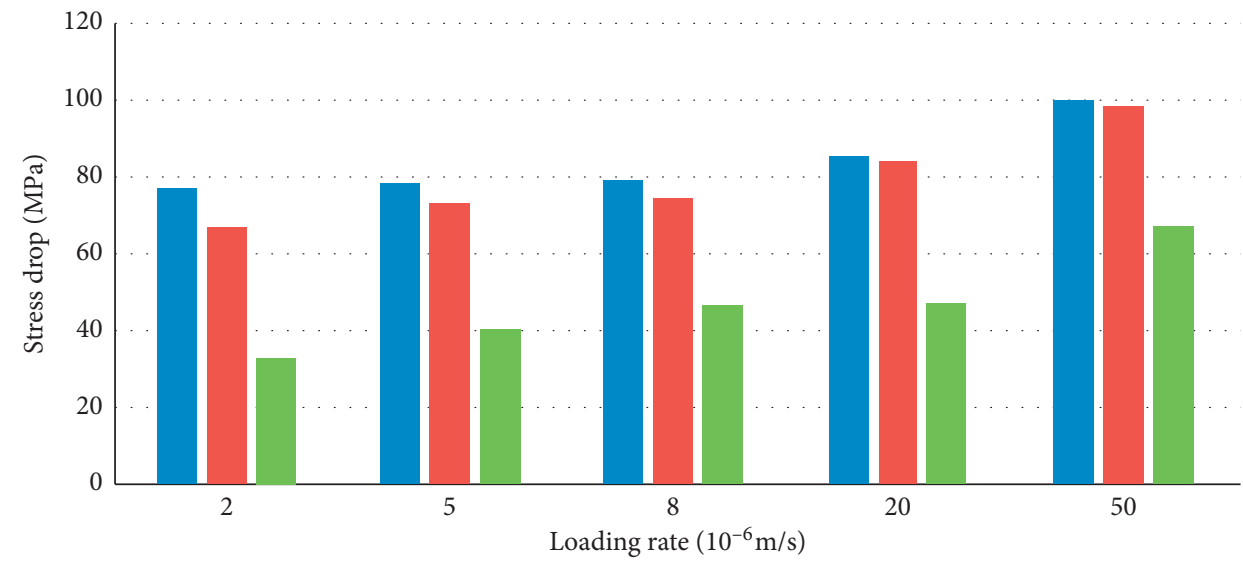

- Numerical specimen C

- Numerical specimen A

- Numerical specimen B

FIGURE 10: Longitudinal contrast of stress drop of three kinds of numerical specimens. 

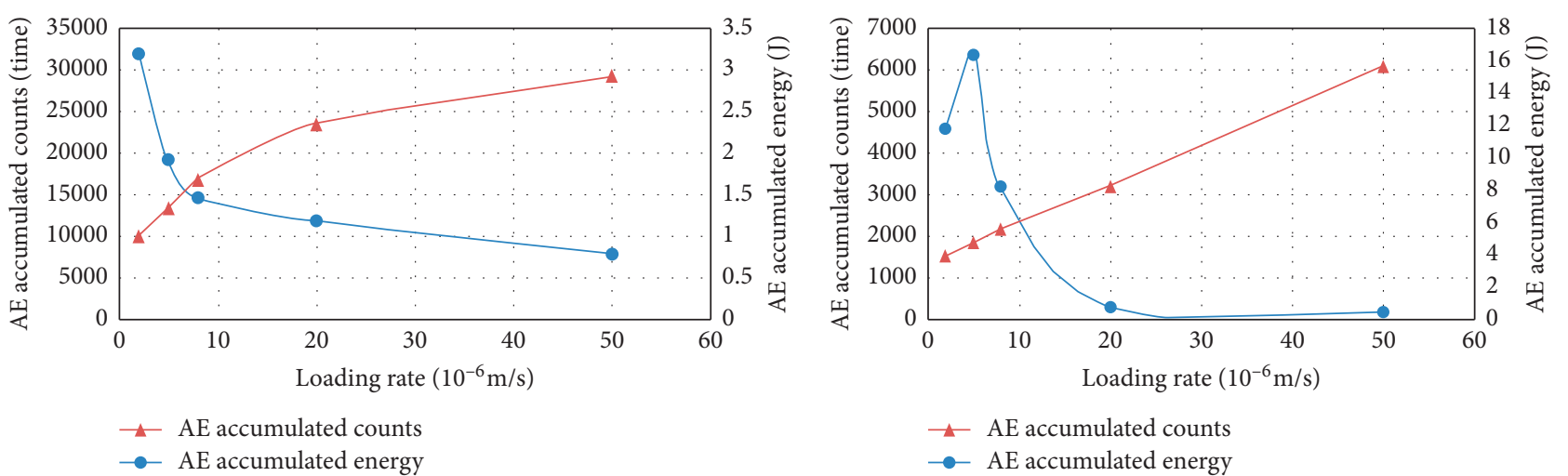

(a)

(b)

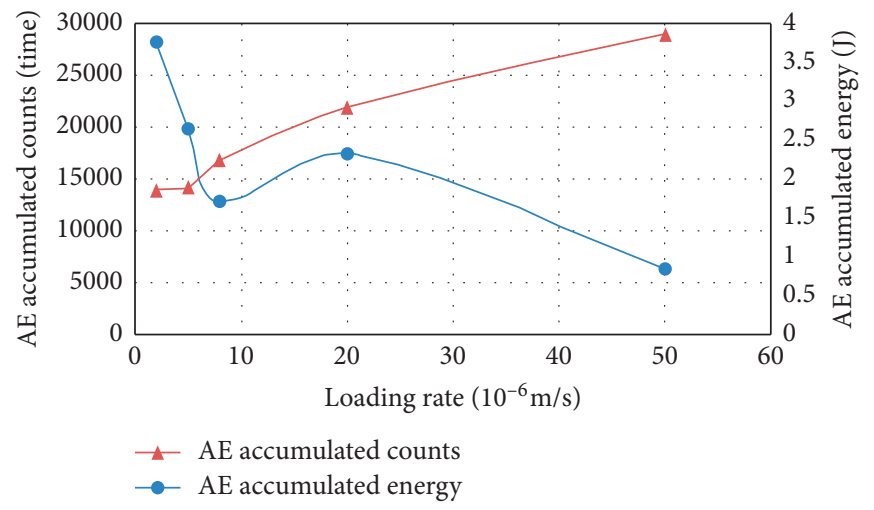

(c)

Figure 11: Relationship curve between AE accumulated energy, AE accumulated counts, and loading rate of three kinds of numerical specimen. (a) Numerical specimen A. (b) Numerical specimen B. (c) Numerical specimen C.

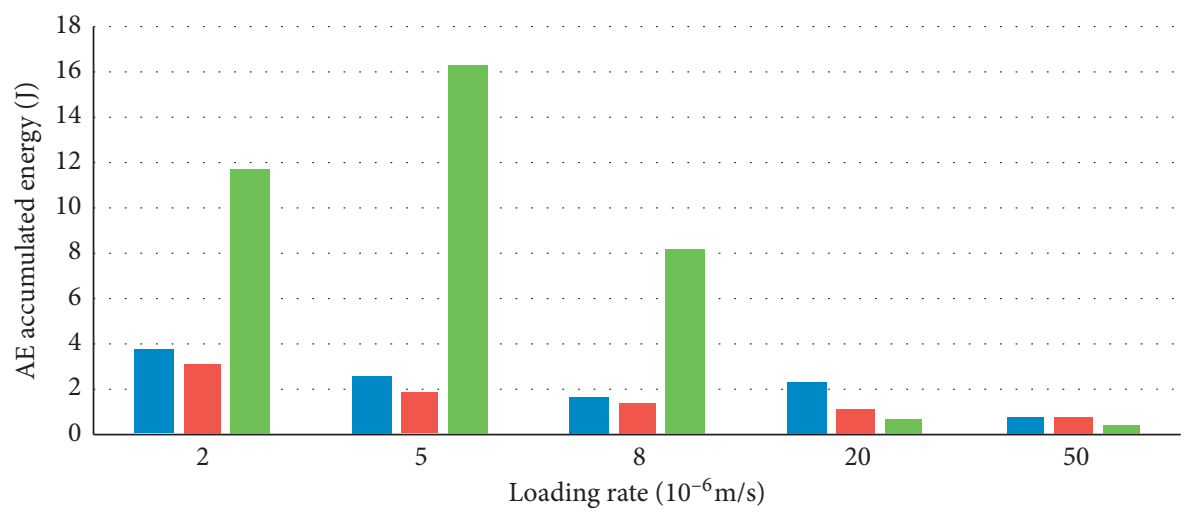

- Numerical specimen C

- Numerical specimen A

- Numerical specimen B

FIGURE 12: Longitudinal contrast of AE accumulated energy of three kinds of numerical specimens. 


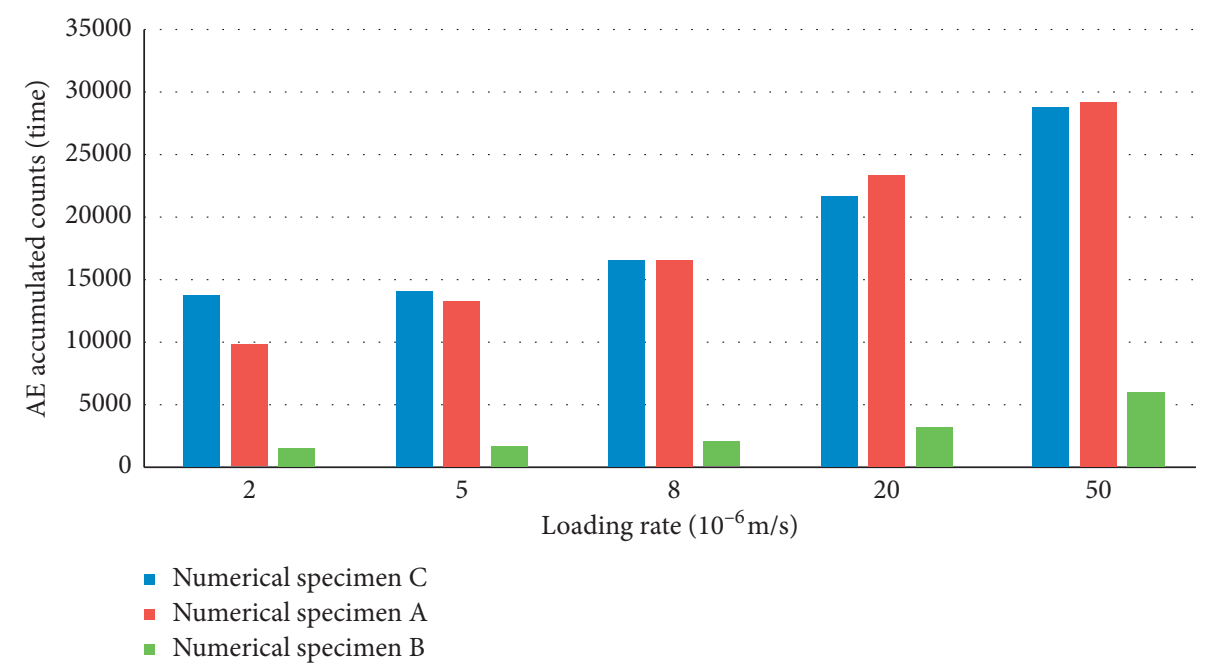

FIgURE 13: Longitudinal contrast of AE accumulated counts of three kinds of numerical specimens.

\section{Conclusions}

In this study, RFPA software is used to build the numerical specimen A of intact rock mass without structural plane, the numerical specimen $\mathrm{B}$ of rock mass with a smooth transfixion structural plane, and the numerical specimen $\mathrm{C}$ of rock mass with transfixion regular sawtooth structural plane. The uniaxial compression numerical tests under different loading rates are carried out. The following conclusions are obtained:

(1) Based on the analysis of the failure characteristics, it is found that the location of the main failure zone varies greatly with the increase of loading rate due to the existence of sawtooth structures, and the failure modes of rock mass become more sophisticated. From the acoustic emission picture, it can be found that the red circle dominates the damage zone, indicating that the failure mode of the specimen is tensile failure.

(2) From the horizontal comparison, the peak strength and stress drop of the numerical specimen $\mathrm{C}$ show the identical law as that of the numerical specimen $\mathrm{A}$ and the numerical specimen $B$; that is, the peak strength and stress drop grow with the increase of loading rate. Moreover, the peak strength of the sample $\mathrm{C}$ is approximate linear relationship with the loading rate. From the overall trend, the residual strength of the numerical specimens $\mathrm{A}, \mathrm{B}$, and $\mathrm{C}$ also rises with the increase of loading rate.

(3) On the basis of the longitudinal comparison, the peak strength and stress drop of the numerical specimen $\mathrm{C}$ are higher than those of the numerical specimen $\mathrm{A}$ and the numerical specimen $\mathrm{B}$. When the loading rate is $0.002 \mathrm{~mm} / \mathrm{s}$, the residual strength of the numerical specimen $\mathrm{C}$ is the lowest, but when the loading speed is $0.005 \mathrm{~mm} / \mathrm{s}-0.05 \mathrm{~mm} / \mathrm{s}$, the residual strength of the numerical specimen $\mathrm{C}$ is the highest.
(4) The AE accumulated counts at three kinds of numerical specimen destruction increase with increasing loading rate; however, the $\mathrm{AE}$ accumulated energy as a whole decreases gradually with the increase of loading rate. Therefore, the law of $\mathrm{AE}$ accumulated counts is contrary to the law of $\mathrm{AE}$ accumulated energy.

(5) In the future compression test, not all the structural surfaces should be considered as smooth, and the fluctuation state of the structural surface should be taken into account. It depends on the specific situation.

\section{Data Availability}

The data used to support the findings of this study are available from the corresponding author upon request.

\section{Conflicts of Interest}

The authors declare that they have no conflicts of interest regarding the publication of this paper.

\section{Acknowledgments}

This study was supported by the National Natural Science Foundation of China (No. 41572249).

\section{References}

[1] B. G. H. Brady and E. T. Brown, Rock Mechanics for Underground Mining, Boston, USA, 1985.

[2] J. Zhao, Q. Liu, K. W. Lee, V. Choa, and C. I. Teh, "Underground cavern development in the Jurong sedimentary rock formation," Tunnelling and Underground Space Technology, vol. 14, no. 4, pp. 449-459, 1999.

[3] D. Huang, R. Q. Huang, and P. Lei, "Shear deformation and strength of through-going saw-tooth rock discontinuity," Journal of China Coal Society, vol. 39, no. 7, pp. 1229-1237, 2014. 
[4] Q. Yu, "Study on rockburst nucleation process and early warning method of deep-buried tunnels," $\mathrm{Ph}$. D. Thesis, Dalian University of Technology, Dalian, China, 2016.

[5] P. Jia and C. A. Tang, "Numerical study on failure mechanism of tunnel in jointed rock mass," Tunnelling and Underground Space Technology, vol. 23, no. 5, pp. 500-507, 2008.

[6] H. Chen, Z. Zhao, and J. Sun, "Coupled hydro-mechanical model for fractured rock masses using the discontinuous deformation analysis," Tunnelling and Underground Space Technology, vol. 38, pp. 506-516, 2013.

[7] T. L. Blanton, "Effect of strain rates from 10-2 to 10 sec-1 in triaxial compression tests on three rocks," International Journal of Rock Mechanics and Mining Sciences \& Geomechanics Abstracts, vol. 18, no. 1, pp. 47-62, 1981.

[8] C. D. Martin, "The strength of massive Lac du Bonnet granite around underground openings," Ph.D. Thesis, University of Manitoba, Manitoba, Canada, 1993.

[9] Y. S. Li, "Experimental analysis on the mechanical effects of loading rates on red sandstone," Journal of Tongji University Natural Science (China), vol. 23, no. 3, pp. 265-269, 1995.

[10] T. Backers, N. Fardin, G. Dresen, and O. Stephansson, "Effect of loading rate on mode I fracture toughness, roughness and micromechanics of sandstone," International Journal of Rock Mechanics and Mining Sciences, vol. 40, no. 3, pp. 425-433, 2003.

[11] S. J. Yang, S. Zeng, and H. L. Wang, "Experimental analysis of mechanical effects of loading rates on limestone," Chinese Journal of Geotechnical Engineering, vol. 27, no. 7, pp. 786$788,2005$.

[12] K. Fuenkajorn and N. Kenkhunthod, "Influence of loading rate on deformability and compressive strength of three Thai sandstones," Geotechnical and Geological Engineering, vol. 28, no. 5, pp. 707-715, 2010.

[13] F.-Q. Gong, X.-F. Si, X.-B. Li, and S.-Y. Wang, "Dynamic triaxial compression tests on sandstone at high strain rates and low confining pressures with split Hopkinson pressure bar," International Journal of Rock Mechanics and Mining Sciences, vol. 113, pp. 211-219, 2019.

[14] S. K. Ray, M. Sarkar, and T. N. Singh, "Effect of cyclic loading and strain rate on the mechanical behaviour of sandstone," International Journal of Rock Mechanics and Mining Sciences, vol. 36, no. 4, pp. 543-549, 1999.

[15] Y. Kohmura and Y. Inada, "The effect of the loading rate on stress-strain characteristics of tuff," Journal of the Society of Materials Science, Japan, vol. 55, no. 3, pp. 323-328, 2006.

[16] Y. Zhou, Q. Sheng, N. Li, and X. Fu, "The influence of strain rate on the energy characteristics and damage evolution of rock materials under dynamic uniaxial compression," Rock Mechanics and Rock Engineering, vol. 53, no. 8, pp. 38233834, 2020.

[17] C. A. Tang and S. Q. Kou, "Crack propagation and coalescence in brittle materials under compression," Engineering Fracture Mechanics, vol. 61, no. 3-4, pp. 311-324, 1998.

[18] C. A. Tang, W. T. Yang, Y. F. Fu, and X. H. Xu, "A new approach to numerical method of modelling geological processes and rock engineering problems-Continuum to discontinuum and linearity to nonlinearity," Engineering Geology, vol. 49, no. 3-4, pp. 207-214, 1998.

[19] C. A. Tang, L. G. Tham, S. H. Wang, H. Liu, and W. H. Li, "A numerical study of the influence of heterogeneity on the strength characterization of rock under uniaxial tension," Mechanics of Materials, vol. 39, no. 4, pp. 326-339, 2007.

[20] X. X. Men, "Numerical experimental study on hydraulic fracturing mechanism and coupling of seepage and damage of rockmass," Ph.D. Thesis, Northeastern University, Shenyang, China, 2015.

[21] Z. X. Zhang, S. Q. Kou, J. Yu, Y. Yu, L. G. Jiang, and P.-A. Lindqvist, "Effects of loading rate on rock fracture," International Journal of Rock Mechanics and Mining Sciences, vol. 36, no. 5, pp. 597-611, 1999.

[22] S. Okubo, K. Fukui, and X. Jiang, "Loading rate dependency of young's modulus of rock," Shigen-to-Sozai, vol. 117, no. 1, pp. 29-35, 2001.

[23] S. Okubo, K. Fukui, and Q. Qingxin, "Uniaxial compression and tension tests of anthracite and loading rate dependence of peak strength," International Journal of Coal Geology, vol. 68, no. 3-4, pp. 196-204, 2006.

[24] X. B. Wang, "Effect of loading rate on entire deformational characteristics of rock specimen," Rock Soil Mech, vol. 29, no. 2, pp. 353-358, 2008.

[25] M. F. Cai, Rock Mechanics and Engineering, vol. 2, Science Press, Beijing, China.

[26] C. Tang, "Numerical simulation of progressive rock failure and associated seismicity," International Journal of Rock Mechanics and Mining Sciences, vol. 34, no. 2, pp. 249-261, 1997.

[27] S. Zhang, S. Wu, C. Chu, P. Guo, and G. Zhang, "Acoustic emission associated with self-sustaining failure in low-porosity sandstone under uniaxial compression," Rock Mechanics and Rock Engineering, vol. 52, no. 7, pp. 2067-2085, 2018.

[28] C. A. Tang and P. K. Kaiser, "Numerical simulation of cumulative damage and seismic energy release during brittle rock failure-Part I: fundamentals," International Journal of Rock Mechanics and Mining Sciences, vol. 35, no. 2, pp. 113-121, 1998. 